\title{
The understanding of research ethics at health sciences schools in Jordan: a cross- sectional study
}

\author{
Nafez Abu Tarboush ${ }^{*}$, Zaid Alkayed ${ }^{2}$, Karem H. Alzoubi ${ }^{3}$ and Wael K. Al-Delaimy ${ }^{4}$
}

\begin{abstract}
Background: Research ethics is required for high-quality research that positively influences society. There is limited understanding of research ethics in Middle Eastern countries including Jordan. Here, we aim to investigate the level of understanding of research ethics principles among health sciences faculty members in Jordan.

Methods: This is a cross sectional study where faculty members from the University of Jordan were surveyed for their knowledge and, attitude of research ethics principles. The study was conducted in the period between July 2016 to July 2017 using a customized-design questionnaire involving demographic data and participants' contributions toward research, and assessment of participants' knowledge, belief and attitude towards research ethics. Different question-formats have been used including multiple-choice, yes or no, and a four point Likert-type questions. Obtained responses were tabulated according to gender, academic-rank, and knowledge about research ethics principles.
\end{abstract}

Results: The study had a response rate of 51\%. Among the 137 participants of this study, most (96\%) were involved in human and animal research, yet, only $2 / 3$ had prior training in research ethics. Moreover, $91 \%$ believed that investigators should have training in research ethics and $87 \%$ believed that there should be a mandatory postgraduate course on that. The average correct scores for correct understanding of researchers towards research ethics was $62 \%$. Yet, there were some misconceptions about the major ethical principles as only $43 \%$ identified them correctly. Additionally, the role of research ethics committees was not well understood by most of the respondents.

Conclusions: Although there is acceptable knowledge about research ethics, discrepancies in understanding in research ethics principles seems to exist. There is a large support for further training in responsible conduct of research by faculty in health sciences in Jordan. Thus, such training should be required by universities to address this knowledge gap in order to improve research quality and its impact on society.

Keywords: Awareness, Ethical principles, Informed consent, Research ethics committees, Conflict of interest, Authorship, Ownership

\footnotetext{
* Correspondence: natarboush@ju.edu.jo; nafeztarboush@yahoo.com 'Department of Biochemistry and Physiology, School of Medicine, The University of Jordan, Amman 11942, Jordan

Full list of author information is available at the end of the article
}

(c) The Author(s). 2020 Open Access This article is licensed under a Creative Commons Attribution 4.0 International License, which permits use, sharing, adaptation, distribution and reproduction in any medium or format, as long as you give appropriate credit to the original author(s) and the source, provide a link to the Creative Commons licence, and indicate if changes were made. The images or other third party material in this article are included in the article's Creative Commons licence, unless indicated otherwise in a credit line to the material. If material is not included in the article's Creative Commons licence and your intended use is not permitted by statutory regulation or exceeds the permitted use, you will need to obtain permission directly from the copyright holder. To view a copy of this licence, visit http://creativecommons.org/licenses/by/4.0/ The Creative Commons Public Domain Dedication waiver (http://creativecommons.org/publicdomain/zero/1.0/) applies to the data made available in this article, unless otherwise stated in a credit line to the data. 


\section{Background}

The field of research ethics is a complex and everchanging topic. Between international and national guidelines down to individual institutional Research Ethics Committees (RECs) requirements, it is an everpressing necessity for researchers to familiarize themselves with the general ethical concepts and information needed to guarantee research approval and publication and avoidance of retractions.

Various studies have been conducted to assess knowledge and awareness of research ethics among members in different institutions with results showing up to $11 \%$ of investigators agreeing that it is acceptable to fabricate data if it would improve the outcome of a study [1, 2]. A study by Weston K. M.et al. in two medical schools in Australia demonstrated varying attitudes among academic staff and clinicians towards various ethical issues in conducting research [3]. Additionally, a study form the Middle East showed that $28 \%$ of researchers in the region did not obtain ethical clearance for their proposals [4]. El-Dessouky H. F. et al. conducted a study in two dental schools in Saudi Arabia and Egypt; where they demonstrated that less than half of respondents were familiar with research ethics principles, and less than a third were familiar with the functions of RECs [1]

Several research ethics documents currently exist including the Nuremberg code, the Declaration of Helsinki, the Belmont Report, and the International Ethical Guidelines for Biomedical Research Involving $\mathrm{Hu}$ man Subjects. Though there is not a complete consensus among these documents, they still provide key ethical principles for research involving human subjects. Moreover, several countries currently refer to them in their own national guidelines [5,6]. A study of the current research ethics guidelines in Middle Eastern countries revealed varying degrees of development and structure among them, with some countries not having national guidelines at all, and others having up to three guidelines [6].

Jordan has been the first Arab country to enact clinical trials research regulations. The Jordanian clinical trials law is based on Declaration of Helsinki, and it governs all clinical trials research in the country [7] though it has some shortcomings, such as regarding guidelines concerning research involving children [8, 9]. Recent studies have assessed knowledge and attitudes towards research ethics in various groups. A study has demonstrated favorable attitudes of researchers towards RECs [10]. Another study found that very few resident doctors had knowledge of The Declaration of Helsinki, and only 36\% had prior clinical research experience [11]. Efforts to increase medical students' and residents' exposure to research are being implemented at University of Jordan
(JU) medical school with the implementation of a mandatory research project for students, and a mandatory publication for residents' prior graduation. However, mandatory research ethics courses or workshops are not being incorporated yet.

$\mathrm{JU}$ is the first public university in Jordan, it has currently the largest number of faculty members and students, and there have been guidelines and a research ethics committee since late 1990s. It is clear from the literature that current research ethics education and regulations have not fully translated into proper knowledge and attitudes throughout the world. This study aims to assess the current understanding of research ethics among faculty members of health sciences schools (HSS) at JU as an example for the country and the region.

\section{Methods}

\section{Study design}

A cross-sectional survey was conducted in the period between July 2016 to July 2017. The questionnaire collection was in person which decelerated the process. The research assistants (trained students) were approaching professors at their offices during their office hours. Some professors were on sabbatical or unpaid leaves while others were unavailable or busy when research assistants approached them which mandates frequent visits. Also, there was some dependence on students' schedule. Furthermore, the study began in the summer when many professors were on summer vacation which stalled the process. Despite the prolonged duration in the collection process, it is unlikely for the results or data interpretation to be affected due to the absence of any formal training program during that period.

The questionnaire of the study was designed to better fit the target group (Additional file 1). It was prepared after reviewing relevant literature [1, 4, 10, 12, 13], and taking the opinions and feedback of faculty in both medical and ethics fields. It was a 4-page questionnaire; the first section inquired about demographic data and participants' contributions toward research. The second section assessed participants' Knowledge, belief and Attitude towards research ethics. Different questionformats have been used; multiple-choice questions were participants can choose more than one answer, yes or no questions, and a four point Likert-type questions (Agree, Disagree, Neutral, and I don't Know). The questions ranged from asking about knowledge regarding ethical guidelines and applications, and requirements for ethics training, mandate of research ethics committees, requirement for informed consent, how to report research misconduct, who owns the data, familiarity with research ethics misconduct terms, and membership of research ethics committees (see tables and figures for description of these questions). Questionnaires which 
were not fully completed were disregarded from analyses.

\section{Study participants}

Members of the health sciences faculty (Lecturers, Assistant Professors, Associate Professors, and Professors) from four HSS (Medicine, Dentistry, Pharmacy, and Nursing) were approached at JU, Amman, Jordan. HSS were chosen for many reasons where convenience in obtaining the questionnaires played a role, and English language proficiency played another important role since the media of instruction and teaching at HSS is English, while it varies at other schools. Any faculty member who is appointed by JU as a full-time employee and can apply for research grants in these four schools was considered eligible which includes all faculty members (367 members including those on sabbatical or unpaid leaves). JU is considered the oldest university in Jordan with the largest number of faculty members (1443 members) and students $(\approx 50,000$ students $)$. Lists of faculty member names were obtained and were approached by research assistants multiple times till they meet the faculty member in person without any prior information about their rank, experience, or their previous ethical training. Faculty who were approachable were 268 members during data collection and those who have fully completed the questionnaire were 137.

\section{Data analyses}

Data were collected and analyzed using EXCEL 16 and GraphPad Prism version 5. Descriptive statistics were used to summarize the data. Correct responses for each question (Additional file 1) were recorded as percentages out of total answers. Likert-type questions were formulated to insure respondents' who are able to strongly pinpoint the correct knowledge or attitude among researchers. Accordingly, the four-point scale has been transformed into a binary scale where the right answer (agree or disagree) was considered correct while other answers where considered incorrect, then percentages of correct answers were calculated and reported. Chisquare test was used for cross-tabulation with gender, type of health school, academic rank, and knowledge regarding publication ethics. Values of $p<0.05$ were considered to be statistically significant.

\section{Results}

Respondents' demographics and experience

Faculty members $(n=137)$ were included in the study with a $51 \%$ response rate. There were 74 (54\%) and 63 (54\%) males and females, respectively. Table 1 shows their demographic characteristics and their distribution according to academic rank, and research experience. Mean age of the participants was $42.2 \pm 11.7$ years. Most respondents were engaged in research projects provided by their publications' record during the last five years. The vast majority of respondents were involved in human or animal research $(n=131,96 \%)$. However, only two thirds of them $(n=87,64 \%)$ had prior research ethics course or training. No statistically significant association was detected linking prior research ethics training with the specific country or region where the respondent had obtained his/her highest academic degree.

\section{Importance of research ethics field}

Majority of respondents (87\%) thought research is bound by ethics and morality. Further, 91\% of respondents thought that all investigators should have training in research ethics, and $87 \%$ of them believed that there should be a mandatory postgraduate course on research ethics (Table 2). Nevertheless, there were misconceptions about the purposes that research ethics should serve among some of the researchers. For example, 25\% of respondents thought that one of the goals of research ethics is to maximize publication quantity, and 15\% of

Table 1 Characteristics of study participants

\begin{tabular}{|c|c|}
\hline Variable & $\mathrm{N}(\%)$ or Mean \pm SEM \\
\hline Age (years) & $42 \pm 5.5$ \\
\hline Gender (Male, Female) & $74,63(54,46)$ \\
\hline \multicolumn{2}{|l|}{ Academic rank } \\
\hline Lecturer & $39(28)$ \\
\hline Assistant Professor & $41(30)$ \\
\hline Associate Professor & $30(22)$ \\
\hline Professor & $27(20)$ \\
\hline Years of experience at the institution & $10.0 \pm 0.9$ \\
\hline Number of publications in the last 5 years & $7.4 \pm 0.7$ \\
\hline Faculty performing projects involving human or animal subjects & $96(70)$ \\
\hline Prior research ethics training or exposure & $64(47)$ \\
\hline
\end{tabular}


Table 2 Knowledge of participants about research ethics with the percentage agreeing to the questions listed in the table and the statistical significance of difference according to gender, academic rank and the faculty they belonged

\begin{tabular}{|c|c|c|c|c|c|}
\hline \multirow[t]{2}{*}{ No. } & \multirow[t]{2}{*}{ Item } & \multirow{2}{*}{$\begin{array}{l}\% \text { of } \\
\text { correct } \\
\text { responses }\end{array}$} & \multicolumn{3}{|l|}{$P$ value } \\
\hline & & & Gender & $\begin{array}{l}\text { Academic } \\
\text { Rank }\end{array}$ & School \\
\hline 1 & All research ethics guidelines apply to all societies and cultures & 25 & 0.81 & 0.24 & 0.44 \\
\hline 2 & Research ethics course should be mandatory in postgraduate programs & 87 & 0.56 & 0.91 & 0.22 \\
\hline 3 & All investigators of human and animal studies should have training in research ethics & 91 & 0.14 & 0.48 & $0.01 *$ \\
\hline 4 & $\begin{array}{l}\text { Not all participants comprehend research projects well. Accordingly, there is no need to provide them } \\
\text { with details }\end{array}$ & 78 & 0.29 & 0.15 & 0.15 \\
\hline 5 & $\begin{array}{l}\text { There is no need to obtain informed consent to do research on blood samples already withdrawn for } \\
\text { clinical tests }\end{array}$ & 70 & 0.56 & 0.30 & $\begin{array}{l}0.00 \\
* * *\end{array}$ \\
\hline 6 & There should be an REC at each university & 88 & 0.23 & 0.22 & 0.49 \\
\hline 7 & Only human subject research must be reviewed by an REC & 69 & 0.26 & 0.07 & 0.27 \\
\hline 8 & Review by an REC would delay research projects and make it harder for the researcher to perform it & 29 & 0.24 & 0.39 & 0.05 \\
\hline 9 & If there is a scientific committee for reviewing research, there is no need for an REC & 78 & 0.29 & 0.72 & 0.84 \\
\hline 10 & Members of the REC should be at least professors with high authority in the university & 64 & 0.08 & 0.34 & 0.59 \\
\hline 11 & $\begin{array}{l}\text { There is no need for child approval in research if they are less than } 15 \text { years as long as parents are } \\
\text { consenting }\end{array}$ & 57 & 0.20 & 0.13 & $0.00 * *$ \\
\hline 12 & Retrospective studies are exempt from informed consent & 39 & 0.88 & 0.84 & 0.05 \\
\hline 13 & $\begin{array}{l}\text { The researcher (by him/herself) can decide that no informed consent is needed if the research is a } \\
\text { retrospective study (data already collected) }\end{array}$ & 56 & 0.63 & 0.82 & 0.20 \\
\hline 14 & Informed consent should be always written & 34 & 0.95 & 0.23 & 0.05 \\
\hline
\end{tabular}

$*{ }^{* *},{ }^{* * *}$ refers to $p$-values $<0.05,<0.01,<0.001$, respectively

them thought that securing personal finances is one of the goals.

\section{Knowledge of research ethics, informed consent, and $\mathrm{REC}$ s role}

$60 \%$ of respondents considered gaining public trust as a major theme of research ethics. Moreover, $75 \%$ of participants considered research ethics as flexible and which can be tailored towards different societies and cultures. In addition, 93\% of participants claimed familiarity with the major ethical principles. However, only $43 \%$ of them could specifically point out the three major ethical principles (Autonomy, Justice, and Non-maleficence). Figure 1 illustrates the familiarity of respondents with certain terms in research ethics and if guidelines exist to regulate-them. Participants were most familiar with Conflict of Interest (COI) and plagiarism (Fig. 1a). However, their familiarity with other terms was less than $50 \%$. Additionally, COI was on top of the list regarding participants' knowledge of existence of guidelines (62\%), while approximately $50 \%$ of participants had knowledge that guidelines existed for other topics (Fig. 1b).

The four point Likert-type questions were directed to assess the general knowledge, attitude, and practice (KAP) of the respondents (Table 2). The average percentage of correct answers to the 14 questions asked was $62 \%$, and the percentage of correct answers for each question was as shown in Table 2. Chi-square analysis of respondents' KAP did not detect any statistically significant association between answering correctly and the participants' gender or academic rank. However, results showed a statistically significant association between being in a specific school and answering correctly for a number of the KAP items (Table 2).

Figure 2a demonstrates respondents' knowledge of RECs roles. A high percentage of respondents thought of REC as a committee to oversee the ethical aspects of research, and to protect the welfare of research subjects (94, 80\%, respectively). Nevertheless, two-third of participants thought of it as a committee to decide if there is a need for informed consent, and only $29 \%$ of participants thought an REC has the right to interfere with the scientific design of the study.

Responses to the question of who should be a member in RECs are displayed in Fig. 2b. A high percentage thought a physician, an ethicist, and a nurse should be members of RECs $(83,64$, and $58 \%$ respectively). On the other hand, approximately one third or less thought a layperson, a government official, or a philosopher are needed as members in RECs.

\section{Data retention, ownership, and authorship}

Almost three quarters $(74 \%, n=102)$ retained documents for over three years, while less than $7 \%$ kept data for less than one year. Respondents also had the choice between sole or shared ownership of data. 


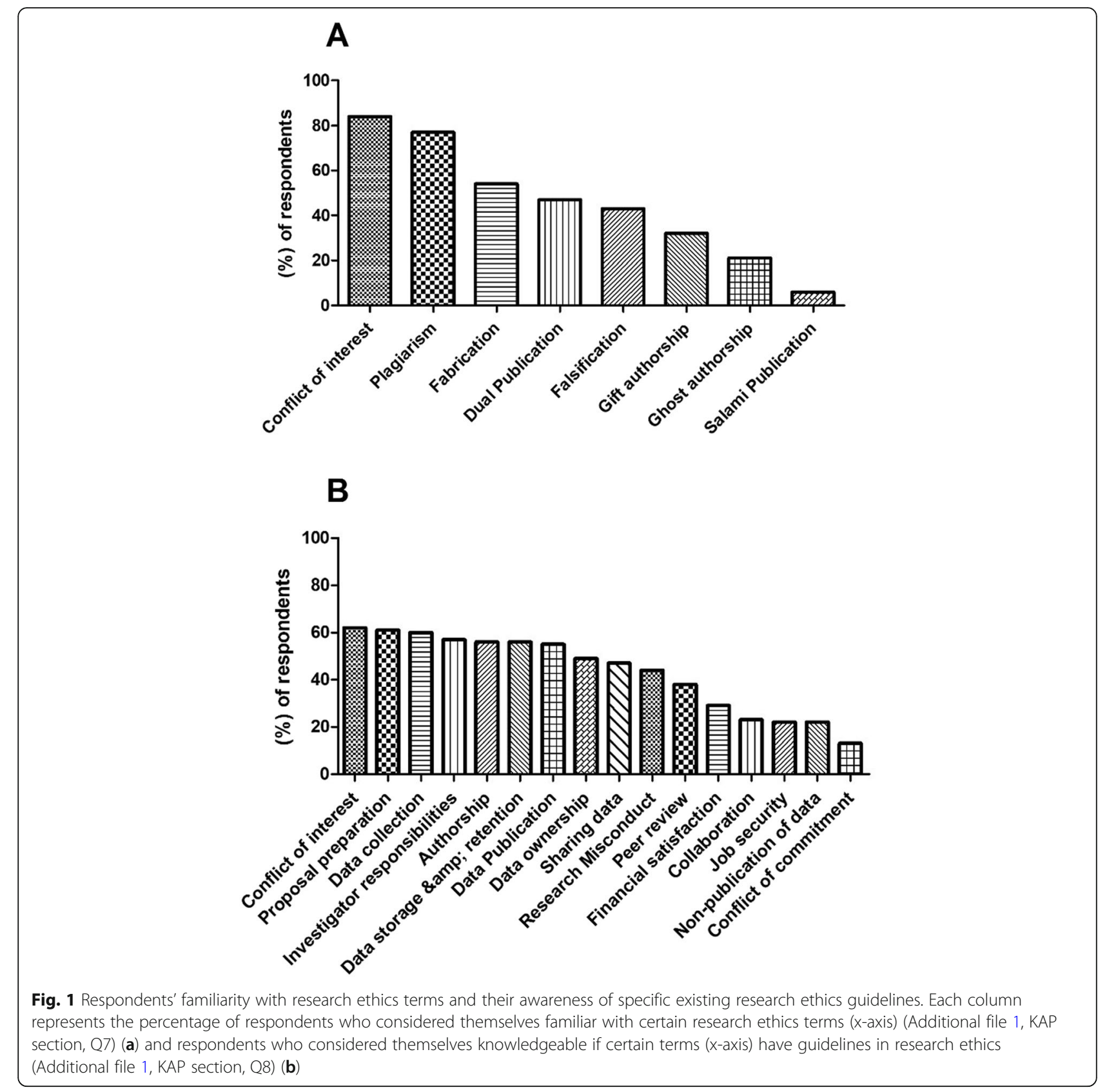

Approximately, $18 \%$ thought of students as a member or the sole owner of the data while 48,43 , and $12 \%$ thought of the Primary Investigator (PI) and collaborators, School or University, and funding agency, respectively, as members or sole owners of the data (Table 3 ).

Results revealed that $39 \%(n=53)$ of respondents answered that as an author you need to be an active part of three processes in any research project; project design, data analysis, and manuscript preparation. Other respondents considered a single activity out of the three qualifies for authorship. Still others, considered further activities such as data collection and being the PI who obtained the funding qualify for an authorship. This indicates the lack of specific adopted guidance of authorship qualification. In addition, analysis found no association of the answers with the academic rank of the respondents.

\section{Discussion}

This study showed contradiction between knowledge and attitude regarding research ethics. There was a deficiency in knowledge regarding the subject of research ethics among study participants. This, however, did not correlate with the respondents' subjective reports of 


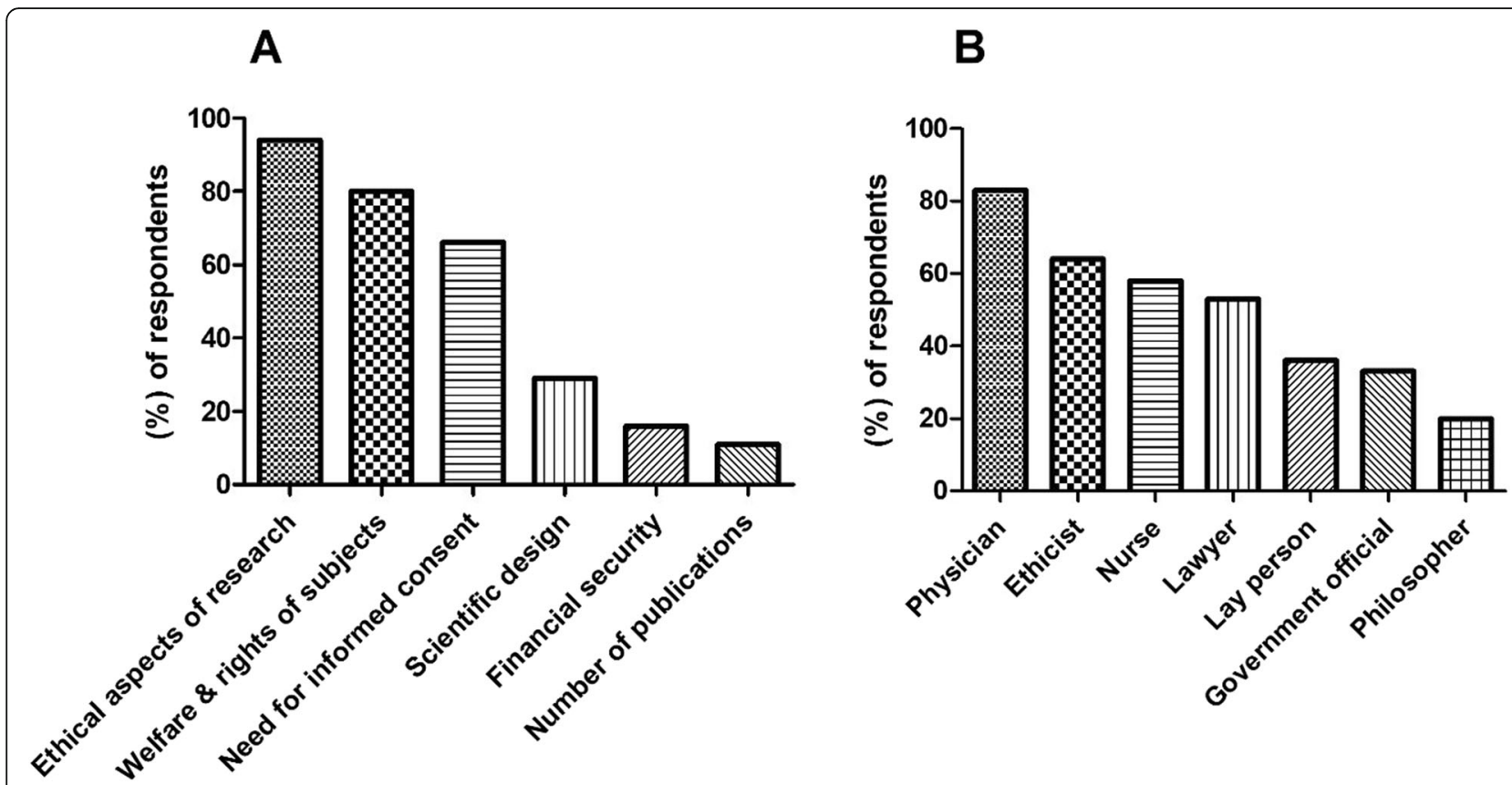

Fig. 2 Perception of RECs role and who should be a member on the committee among respondents. Each column represents the percentage of respondents perceived REC role as the roles assigned in the x-axis (Additional file 1, KAP section, Q11) (a) and their perception of who should be a member of an REC (Additional file 1, KAP section, Q12) (b)

previous ethics training and exposure. On the other hand, $36 \%$ of respondents did not have prior research ethics training. Although this result is comparable to other studies from high-income and low-and-middle-income countries $[1,12,13]$, the majority of respondents (93\%) performed research projects involving humans or animals, which mandates higher level of research ethics training.

Current results revealed a high appreciation of the respondents to the autonomy of research participants (Table 2, items 4 \& 5). However, specific attitudes toward informed consent (Table 2, items 11-14) revealed varying attitudes of respondents in comparison with the published literature [1, 12-17]. Specific issues on informed consent are growing rapidly in the field of research ethics; e.g. the issue of written consent.

Table 3 Responses of participants regarding who should own the data of a study

\begin{tabular}{ll}
\hline Body who should have data ownership & $\%$ \\
\hline PI and collaborating researchers (not including students) & 37 \\
School or university of researcher/s & 33 \\
The graduate student/s (if any) & 10 \\
The granting agency & 4 \\
Shared $^{\text {a }}$ & 16 \\
\hline
\end{tabular}

${ }^{a}$ Response was shared among any combinations of PI, collaborating researchers, school or university of researcher/s, the graduate student $/ \mathrm{s}$, and the granting agency
Approximately, two thirds of respondents believed that informed consent should always be written. Whereas, in fact, the consent should be informed and culturally appropriate regardless of the method of documentation $[18,19]$.

Exempting retrospective studies from informed consent is another issue that has been answered correctly by less than half of participants. It is the RECs that are authorized to make that decision, not the investigator(s).

An important point to stress is the practical and everyday exposure of the participants to research ethics issues at their institutions. In the two questions that asked about familiarity of respondents with research ethics terms and if international guidelines are applied in research ethics topics, the highest percentage scored in both items was for COI. This could be related to manuscript submission process where COI process has to be declared. With that said, in addition to formal ethics training, the implementation of ethical considerations at the level of the institution may provide practical exposure of faculty members to ethical issues that solidifies the theoretical information they gained beforehand.

Respondents had some contradicting understanding and perception about the role of REC, as the majority (88\%) believed that RECs should be created in each university, yet, one third of the respondents believed that project reviewing by an REC would delay research projects approval and/or funding process. These findings corresponds with previous studies reporting excessive 
bureaucracy caused by RECs in Jordan [10] and other Western and Mediterranean countries [1, 20]. This might be related to a perception of respondents about delay rather than an actual delay. Therefore, proposals that aim to ease the process of project approval without compromising ethical or scientific regulations are a necessity, both locally and internationally.

In terms of data ownership; this varies by institutions and usually require compliance with the funding agency or university requirements. Sharing data has become the common rule globally [21]. However, $84 \%$ of respondents chose a single owner, with students having the least rights to ownership. This suggests the idea of single ownership, which should, theoretically, place strict rules on authorship qualifications. However, this was not reflected in current data as many respondents considered a single activity such as data collection qualifies for authorship. With only 39\% of respondents correctly identifying the proper authorship qualification, it seemed more plausible that authorship is seen as a mean for academic promotion rather than being based on merits and project participation. This does in fact echo the argument of "publish or perish" environment [22].

Although only $51 \%$ responded to the current survey, this is similar to other such surveys done elsewhere [23, 24]. This study is potentially underestimating the gap between knowledge and attitude as most of those who responded would likely be interested in the topic and follow ethical guidelines, while those who did not might be less informed and therefore less interested in such a survey. It might also be due to the non-participants being busy clinicians or non-researchers and in such case the results are still an underestimation of the gaps in research ethics knowledge. An appropriate monitoring approach by universities can include mandatory surveys of all researchers applying for REC approval.

Results reported in the current study indicate a possible gap between theoretical knowledge and real world application among participants. This could be reflective of an underlying approach to research ethics being mostly an academic exercise. Moreover, this view is consistent with the current publish-or-perish environment. Academics are pushed to publish research focused on quantity rather than quality, and as such ethical considerations and understanding take a lower position in the researchers' priorities.

\section{Study limitations, strengths, and future directions}

This study is bound to several limitations. First, faculty members who were enrolled and completed the questionnaire not necessarily reflects the entire faculty KAP toward research ethics provided by the response rate of $51 \%$. Second, despite that $\mathrm{JU}$ is the largest university with the biggest number of faculty members, this study still involved only a single institution in Jordan, which could limit the generalizability of our results. Further studies that involve other schools at JU and other universities in Jordan are encouraged and necessary to evaluate the baseline of research ethics KAP among our researchers. Furthermore, we did not investigate the type of previous training of researchers, which might impact their KAP toward research ethics and give a clearer vision of what is recommended to implement in the future at the institution. On the other hand, the study revealed some interesting points. Firstly, there appears to be an acceptance of RECs among the faculty, which is in accordance to what researchers believe at another institution in Jordan [10]. Second, there seems to be a need for formal education in research ethics among all faculty levels, which is also in accordance a previous study of medical residents' beliefs in Jordan [11]. Finally, consideration for qualitative or mixed methods methodology in future would be sensible as the qualitative components would be highly informative and instructional for further progress of any training.

\section{Conclusions}

Although researchers seem to have acceptable knowledge about research ethics, discrepancies in understanding research ethics principles seems to exist. Thus, formal mandatory training in research ethics with further evaluation and research should be considered for all research-involved personnel at different undergraduate and postgraduate level. Furthermore, institutional regulations and oversight of research projects are a cornerstone to prevent misconduct. More stringent processes of approving research with constructive feedback from knowledgeable reviewers may increase awareness and knowledge indirectly by forcing researchers to adhere to ethical guidelines or face rejections.

\section{Supplementary information}

Supplementary information accompanies this paper at https://doi.org/10. 1186/s12909-020-02040-5.

\section{Additional file 1.}

\section{Abbreviations}

COI: conflict of interest; HSS: health sciences schools; JU: The University of Jordan; KAP: knowledge, attitude, and practice; PI: primary investigator; REC: research ethics committee

\section{Acknowledgements \\ The authors would like to thank the funding source and all faculty members who participated in the study.}

\section{Authors' contributions}

All authors have read and approved the manuscript. NAT contributed in study design, analysis, and interpretation of data and wrote the manuscript draft. KHA and WKA were involved in the study design, data analysis, interpretation and statistics, and revised the draft. ZA has contributed to 
study design, and acquisition and interpretation of data, he was also involved in drafting the manuscript.

\section{Funding}

Work on this project was supported by grant \# 5R25TW010026-02 from the Fogarty International Center of the U.S. National Institutes of Health on behalf of the Research Ethics Program in Jordan. The funding source encourages development of research ethics projects in Jordan. A full report has been sent to Research Ethics Program in Jordan for record purposes and permission for publication has been granted.

\section{Availability of data and materials}

The datasets used and/or analyzed during the current study are available from the corresponding author on reasonable request.

\section{Ethics approval and consent to participate}

Jordan University Hospital IRB Committee has approved this study (ref. \# 10/ 2016/15633). All participants were asked for their verbal informed consent prior to inclusion in this study, and once the participant agreed to participate, he/she were handed the questionnaire to fill it and return it back. IRB committee has approved the informed consent to be verbal since it is a questionnaire and will be filled by participants who are researchers themselves.

\section{Consent for publication}

Permission for publication has been granted by Research Ethics Program in Jordan which is supported by Fogarty International Center of the U.S. National Institutes of Health.

\section{Competing interests}

The authors declare that they have no competing interests.

\section{Author details}

'Department of Biochemistry and Physiology, School of Medicine, The University of Jordan, Amman 11942, Jordan. ${ }^{2}$ Internal Medicine Unit, Psychiatry Division, Jordan University Hospital, Amman, Jordan. ${ }^{3}$ Department of Clinical Pharmacy, Jordan University of Science and Technology, Irbid, Jordan. ${ }^{4}$ Department of Family Medicine and Public Health, University of California San Diego, San Diego, CA, USA.

Received: 10 December 2019 Accepted: 13 April 2020

Published online: 21 April 2020

\section{References}

1. El-Dessouky HF, Abdel-Aziz AM, Ibrahim C, Moni M, Abul Fadl R, Silverman H. Knowledge, Awareness, and Attitudes about Research Ethics among Dental Faculty in the Middle East: A Pilot Study. Int J Dent. 2011:694759.

2. Fanelli D. How many scientists fabricate and falsify research? A systematic review and meta-analysis of survey data. PLoS One. 2009;4(5):0005738.

3. Weston KM, Mullan JR, Hu W, Thomson C, Rich WC, Knight-Billington P, Marjadi B, McLennan PL. Academic Guidance in Medical Student Research: How Well Do Supervisors and Students Understand the Ethics of Human Research? J Acad Ethics. 2016;14(2):87-102.

4. Abdur Rab M, Afzal M, Abou-Zeid A, Silverman H. Ethical practices for health research in the Eastern Mediterranean region of the World Health Organization: a retrospective data analysis. PLoS One. 2008;3(5):e2094.

5. Bernabe RD, van Thiel GJ, van Delden JJ. What do international ethics guidelines say in terms of the scope of medical research ethics? BMC Med Ethics. 2016;17:23.

6. Alahmad G, Al-Jumah M, Dierickx K. Review of national research ethics regulations and guidelines in Middle Eastern Arab countries. BMC Med Ethics. 2012;13(34):1-10.

7. Al-Omari A, Al-Hussaini M. Research ethics governance in the Arab region: Jordan. In: Research ethics in the Arab region Volume 5, 1st edn. Edited by Silverman H. Germany: Springer; 2017. p. 221-8.

8. Ramahi I, Silverman H. Clinical research law in Jordan: an ethical analysis. Dev World Bioeth. 2009;9(1):26-33.

9. Khabour OF, Alomari MA, Al-Sheyab NA. Parental Perceptions About Informed Consent/Assent in Pediatric Research in Jordan. J Empir Res Hum Res Ethics. 2017;12(4):261-8.
10. Rababa'h AM, Alzoubi KH, Ababneh M, Khabour OF. Awareness of Jordanian Investigators About the Importance of Ethics Review Committees: A Pilot Study. Sci Eng Ethics. 2020;26(2):821-31.

11. Al Demour S, Alzoubi KH, Alabsi A, Al Abdallat S, Alzayed A. Knowledge, awareness, and attitudes about research ethics committees and informed consent among resident doctors. Int J Gen Med. 2019;12:141-5.

12. Gopinath NM, John J, Senthilkumar E, Nagappan N. Knowledge awareness and attitude about research ethics among dental faculties in India. J Contemp Dent Pract. 2014;15(5):608-13.

13. Reddy R, Ramya K, Raju MAVK, Rayudu G, Kiran C, Jyothirmai K. Knowledge, awareness and attitudes about research ethics among dental professionals in a dental institution of south India. Journal of Education and Ethics in Dentistry. 2013;3(1):34-9.

14. Munoli S, Niveditha G, Deepthi R. Knowledge, attitude and practice of research ethics among medical faculty in a teaching hospital. Int J Basic Clin Pharmacol. 2017;6(4):913-8.

15. Nakkash R, Qutteina Y, Nasrallah C, Wright K, El-Alti L, Makhoul J, Al-Ali K. The Practice of Research Ethics in Lebanon and Qatar: Perspectives of Researchers on Informed Consent. J Empir Res Hum Res Ethics. 2017;12(5): 352-62.

16. Taiwo OO, Kass N: Post-consent assessment of dental subjects' understanding of informed consent in oral health research in Nigeria. BMC Med Ethics 2009;10:11.

17. Silverman $\mathrm{H}$, Edwards $\mathrm{H}$, Shamoo A, Matar A. Enhancing research ethics capacity in the Middle East: experience and challenges of a Fogartysponsored training program. J Empir Res Hum Res Ethics. 2013;8(5):40-51.

18. CIOMS. International ethical guidelines for health-related research involving humans. In., 4th edn. Geneva: Council for the International Organizations of Medical Sciences (CIOMS); 2016.

19. Resnik DB. The Ethics of Research with Human Subjects: Protecting People, Advancing Science, Promoting Trust, vol. 74, 1st edn. USA: Springer; 2018.

20. Mallick AA, O'Callaghan FJ. Research governance delays for a multicentre non-interventional study. J R Soc Med. 2009:102(5):195-8.

21. Steneck NH. Introduction to the Responsible Conduct of Research, 2nd edn Washington: US Government Printing Office; 2007.

22. Guraya SY, Norman RI, Khoshhal Kl, Guraya SS, Forgione A. Publish or Perish mantra in the medical field: A systematic review of the reasons, consequences and remedies. Pak J Med Sci. 2016;32(6):1562-7.

23. Panjiar $\mathrm{P}$, Kochhar $\mathrm{A}$, Vajifdar $\mathrm{H}$, Bhat K. A prospective survey on knowledge, attitude and current practices of pre-operative fasting amongst anaesthesiologists: A nationwide survey. Indian J Anaesth. 2019;63(5):350-5.

24. Wilkinson TA, Russell CJ, Bennett WE, Cheng ER, Carroll AE. A cross-sectional study of predatory publishing emails received by career development grant awardees. BMJ Open. 2019:9(5):e027928.

\section{Publisher's Note}

Springer Nature remains neutral with regard to jurisdictional claims in published maps and institutional affiliations.
Ready to submit your research? Choose BMC and benefit from:

- fast, convenient online submission

- thorough peer review by experienced researchers in your field

- rapid publication on acceptance

- support for research data, including large and complex data types

- gold Open Access which fosters wider collaboration and increased citations

- maximum visibility for your research: over $100 \mathrm{M}$ website views per year

At $\mathrm{BMC}$, research is always in progress.

Learn more biomedcentral.com/submissions 